\title{
THE DARBOUX PROBLEM FOR HYPERBOLIC FUNCTIONAL DIFFERENTIAL EQUATIONS AND INEQUALITIES IN THE SENSE OF CARATHÉODORY
}

\section{ADRIAN KARPOWICZ}

Abstract. We consider the linear and nonlinear problem for partial functional differential equations

$$
\begin{gathered}
\frac{\partial^{2} u}{\partial x \partial y}(x, y)=C(x, y) u(x, y)+P(x, y) u_{(x, y)} \text { a.e. in }[0, a] \times[0, b] \\
\frac{\partial^{2} u}{\partial x \partial y}(x, y)=f\left(x, y, u_{(x, y)}, u(x, y)\right) \text { a.e. in }[0, a] \times[0, b]
\end{gathered}
$$

with Darboux condition

$$
u(x, y)=\psi(x, y) \text { on }\left[-a_{0}, a\right] \times\left[-b_{0}, b\right] \backslash(0, a] \times(0, b]
$$

where the Hale operator $u_{(x, y)}:\left[-a_{0}, 0\right] \times\left[-b_{0}, 0\right] \rightarrow R^{n}$ is defined by $u_{(x, y)}(s, t)=u(s+x, t+$ $y)$ for $(s, t) \in\left[-a_{0}, 0\right] \times\left[-b_{0}, 0\right]$. We give a few theorems about weak and strong inequalities and the existence theorem for the nonlinear problem.

Mathematics subject classification (2010): 35L70, 35R10, 35R45.

Keywords and phrases: Functional differential inequalities, functional differential equations, hyperbolic equations, Darboux problem, solutions in the sense of Carathéodory.

\section{REFERENCES}

[1] S. BRZYCHCZY AND J. JANus, Monotone Interative Methods for Nonlinear Integro-Differential Hyperbolic Equations, Univ. Iagell. Acta Math., 37 (1999), 246-261.

[2] T. CZŁapińsKi, Interative Methods for Darboux Problem for Partial Functional Diffrential Equations, J. of Inequal. \& Appl., 4 (1998), 141-161.

[3] M. HIRSCH, System of Diffrential Equations that are Competitive or Cooperative, II: convergence almost everywhere, SIAM J. Math. Anal., 16 (1985), 423-439.

[4] V. Lakshmikantham And S. Leela, Differential and Integral Inequalities, Vol. I, Academic Press, New York, 1969.

[5] V. Lakshmikantham and S. Leela, Differential and Integral Inequalities, Vol. II, Academic Press, New York, 1969.

[6] A. Pelczar, Some functional differential equations, Disser. Math., 100 (1973), 3-74.

[7] J. SZARS KI, Differential Inequalities, Warszawa, 1967.

[8] W. Walter, On strongly monotone flows, Ann. Pol. Math., 66 (1997), 269-274.

[9] W. WALTER, Ordinary Functional Differential Equations and Inequalities in the Sense of Carathéodory, Applicable Analisis, 70, 1-2 (1998), 85-95.

[10] W. WALter, Differential and Integral Inequalities, Springer, 1970. 